\title{
Partial Anomalous Pulmonary Venous Return
}

National Cancer Institute

\section{Source}

National Cancer Institute. Partial Anomalous Pulmonary Venous Return. NCI Thesaurus.

Code C99004.

A congenital heart disorder in which one or two pulmonary veins are not connected to the left atrium and drain into the right atrium instead. It may lead to arrhythmias and pulmonary hypertension. 